\title{
RISK PROSPECTS AND CHALLENGES IN THE ROMANIAN ECONOMY
}

\author{
Dalis Maria Drăghici \\ Institute of Doctoral Studies, "Lucian Blaga" University, Sibiu, Romania \\ dalis.draghici@ulbsibiu.ro
}

\begin{abstract}
Tackling challenges in order to promote competitiveness in various economic sectors requires understanding and approaching the risk assessment as an essential factor that can anytime determine the availability of the mechanisms and resources needed for a sustainable future. Although a certain amount of risk has to be assumed, losses caused by specific events appear to be broader than gains. In order to ensure economic growth, it is challenging for governments to try to manage the exposure to losses, this being the reason why they play a key role in fundamental prediction and in finding the most suitable evaluation tools. Despite the struggle against global strains and political risks, uncertainty not only persists in association with the external environment, but it reached extremely exalted levels compared to recent history. The instability of the global environment is leading to a lot of economic decisions being put on pause. Uncertainty's effects about a nation's economic policies can often spread beyond the country's borders, this being the reason why a possible deterioration of the macroeconomic equilibrium is expected to have a significant impact on the risk perception, with direct consequences upon the Romanian economy. The aim of this article is to outline not only the existing economic framework in Romania, but also its future development in a macroeconomic context driven by uncertainty.
\end{abstract}

Keywords: country risk assessment; macroeconomic confidence index; Romania's economic perspectives

JEL classification: E66

\section{Introduction}

This paper aims to outline an image of how Romania's economy will look like in the next decade, in a global macroeconomic climate challenged with a certain degree of risk. Through this paper, we will be able also to see what 2018 is supposed to bring us and if the perspectives are going to be satisfying. The hypothesis on which the present article is built lays in the fact that although Romania is perceived as having a reasonable financial and business outlook, it can exhibit shortcomings anytime, in which the political context can release deep pressure. Also, in order to achieve the paper's objectives, an enlarged significance has been placed on appraisal by which countries can be sorted when approaching the risk perspective, assessment made by reliable sources like World Economic Forum (WEF), European Systemic Risk Board (ESRB), Compagnie Française d'Assurance pour le Commerce Extérieur (COFACE), or Chartered Financial Analysts (CFA).

This article is structured in 7 sections, as follows: part two reveals some risks prospects and challenges in order to promote competitiveness in various economic sectors, while in the third section, the macroeconomic global context is being presented, where uncertainty persists. Summarizing the next chapter, I have chosen the Global Economic Policy Uncertainty Index to emphasise the fact that the entire world is facing record levels of uncertainty, all because the regions of the global economy are interdependent. Through section number 5 some risk forecasts for the European Union are being detailed. The sixth part not only investigates, in an empirical manner, how financial analysts foresee the 
Romanian economic context, but also analysis the local entities that have the power to influence the economy in the future. Chapter seven briefs the main ideas of the paper and suggests some suitable future ways of action.

Before continuing with the second chapter, it's important to mention that segments of the present paper have been already discussed during the Doctoral Symposium in Economic Sciences: 'Romania and the challenges of economic development. The response of young researchers', which took place in Oradea, Romania (23 ${ }^{\text {rd }}$ November 2017). The conference was followed by publications in the Proceedings of the $8^{\text {th }}$ Conference of Doctoral Students in Economic Sciences.

\section{Perspectives on risk}

Tackling challenges in order to promote competitiveness in various economic sectors requires understanding and approaching the risk assessment as an essential factor that can anytime determine the availability of the mechanisms and resources needed for a sustainable future.

Although a certain amount of risk has to be assumed, losses caused by specific events appear to be broader than gains. This is mainly because some human beings are more risk averse and may prefer to have a cautionary action towards them, or as Tversky and Kahneman used to say: „People's willingness to bet on an uncertain event depends not only on the degree of uncertainty but also on its source" (Tversky, Kahneman, 1992).

A certain fact is that people vary in terms of approaching the decision-making process, perceiving the certainty equivalents to the same risk distinctively. This is why it is vital to understand this heterogeneous frame, which makes it disputable if a homogeneous assessment of risk can be attained. In order to understand the complexity of risk, it is useful to mention that some of the first insurance companies were structured in such a way so the vulnerability to shocks to be diminished. It was 1666 when the great Fire of London destroyed properties worth $£ 10$ million, a figure estimated to be around one-quarter of the total gross domestic product of England at the time (Besanko et al., 2010). So, after this unexpected tragedy, the Londoners examined the possible ways of action in order to secure their wealth and to share the outcomes of other unforeseen uncertainties. This is why, in 1696, a group of 100 people set up a mutual insurance company, based on their wealth, forming a budget in case of other unwanted events.

The most important aspect and part of the risk management is that it has to be distributed over time, its effects being extended more broadly over the long term, with benefits often less visible, whereas the efforts tend to be observable immediately. Any deprivation of indicators for risk that are committed to some long-term objectives leads to a barrier when trying to monitor decision-makers accuracy and performance. Defining an acceptable level of risk is difficult because of the complexity of the process for determining its distribution and because of the wide differences in preferences, values and believes (World Development Report, 2017). In order to ensure economic growth, it is challenging for governments to try to manage the exposure to losses, this being the reason why they play a key role in fundamental prediction and in finding the most suitable evaluation tools.

\section{Macroeconomic Global Context}

Globally, inequality between countries has been decreasing with an accelerating rhythm over the past 30 years (World Economic Forum, 2017), but despite the struggle against global strains and political risks, uncertainty persists in association with the external environment. This refers especially to Brexit negotiations, US economic policies, the conduct of monetary policies led by FED (Federal Reserve System) and ECB (European Central Bank) and their consequences on the entire macroeconomic global framework. 
Also, of relevance is the future development of the Chinese economic activity and from other emerging economies, through the impact they have on economic growth. But, as socio-economic effects are "increasingly determined globally" (World Economic Forum, 2017), the anger resides in the incapability of national policies to assure stability.

The world we live in turns to be more and more complex, but also interconnected, making possible breakdowns dramatic, but in the same time realistic. A landscape that is always shifting and evolving is proving us that when it comes to composite systems, the risks follow the same path, because of the various intersections between the financial systems, societies together with their economies and ecosystems.

Recent advances in sciences and the new technologies available boosted our confidence and expertise in identifying trends, evaluating risk and initiating cautions. Despite this, in order to manage risk effectively, it is important to understand the fact that the behavioural part is essential. It's been proved that when it comes to larger risks, our decisions are less competent, to both identifying them, but also to materializing the knowledge into fruitful results.

For the ongoing year, The Global Risk Report synthetizes in the most comprehensible way the idea that the accelerated environment, together with the interconnectedness that exists in every domain should have the role of mitigating the damages caused by all complex movements. In order to rely on proofs and examples, we should take a closer look on how the short-term future will be, with the environmental issues in foreground, not only in terms of likelihood, but also of impact.

Tabel 1: Global Risks in 2018

\begin{tabular}{|c|c|}
\hline LIKELIHOOD & IMPACT \\
\hline 1. Extreme weather events & 1. Weapons of mass destruction \\
\hline 2. Natural disasters & 2. Extreme weather events \\
\hline 3. Cyberattacks & 3. Natural disasters \\
\hline 4. Data fraud or theft & 4. Failure of climate-change mitigation and adaptation \\
\hline 5. Failure of climate-change mitigation and adaptation & 5. Water crises \\
\hline 6. Large-scale involuntary migration & 6. Cyberattacks \\
\hline 7. Man-made environmental disasters & 7. Food crises \\
\hline 8. Terrorist attacks & 8. Biodiversity loss and ecosystem collapse \\
\hline 9. Illicit trade & 9. Large-scale involuntary migration \\
\hline 10. Asset bubbles in a major economy & 10. Spread of infectious diseases \\
\hline
\end{tabular}

Source: World Economic Forum (The Global Risks Report 2018 - 13th Edition)

A possible deterioration of the macroeconomic equilibrium is expected to have a significant impact on foreign investors' risk perception, with direct consequences on the stable cash flows that are directed towards Romanian economy. This is why is so crucial to maintain a balanced mixture of policies that can assure an endurance in facing potential turbulences.

\section{Uncertainty Index}

According to European Systemic Risk Board (2016), "economic policy uncertainty in the EU was at all-time high", reaching the peak (309.88) in December 2016, while in 2008, during the global financial crisis the economic policy uncertainty index registered a value of only 200.94. It was the first time ever when the value of the index surpassed the frontier of 300 , meaning three times the average number over the past 20 years (as far back as the index goes), as stated in Washington Post. 


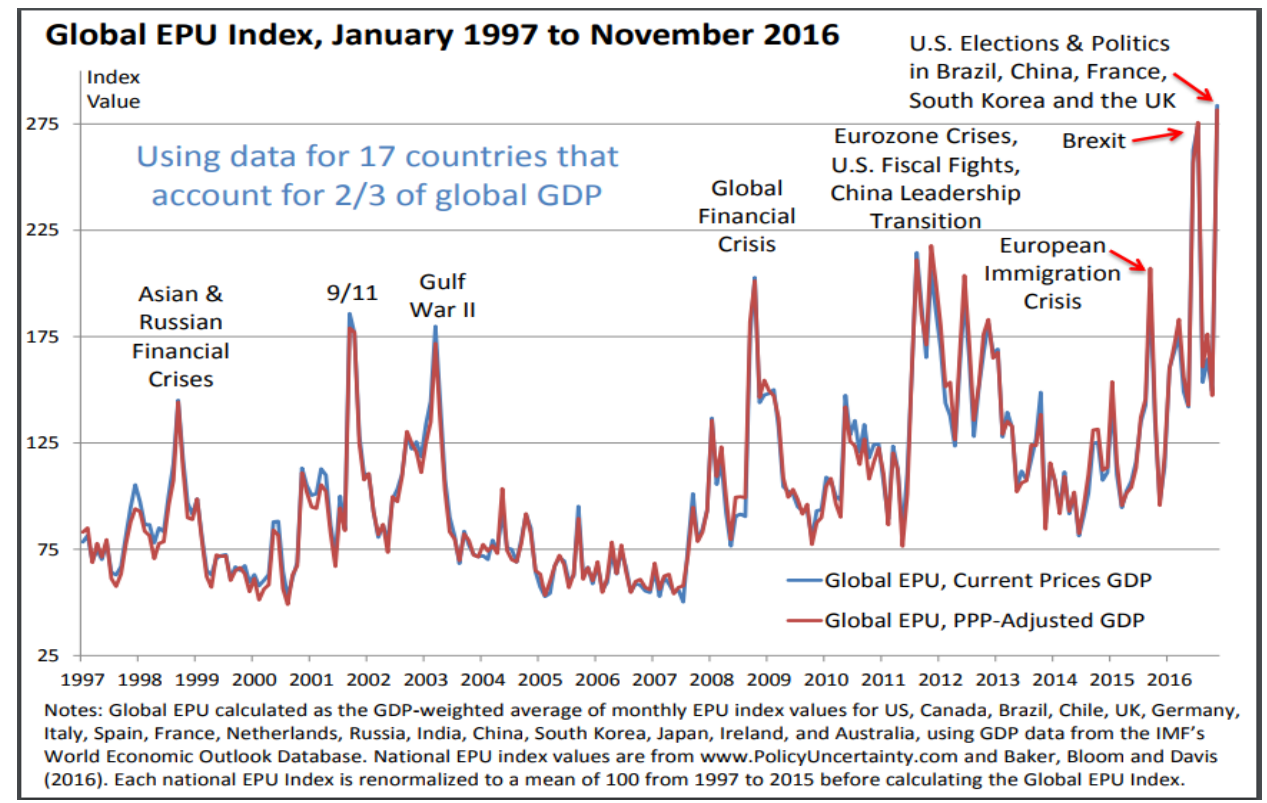

Figure 1: Trends in the Uncertainty Index

Source: Economic Policy Uncertainty (www.policyuncertainty.com/)

Scott Baker (Northwestern University), along with Nicholas Bloom (Stanford University) and Steven Davis (University of Chicago) developed an index in 1997 in order to globally measure the degree of uncertainty, combining data from 18 different countries. These countries represent more than two thirds of the global economy.

The index built is mainly based on text research from news articles (The Washington Post, The New York Times, Wall Street Journal and so on) and aims to capture information about who will take some important steps, when and what economic policy decisions will be undertaken and the economic consequences of all these actions (Baker, Bloom, Davis, 2016).

The finance experts and economists who are looking for interdependencies between different regions of the global economy and political economic uncertainty are suggesting that the entire world is facing record levels of uncertainty and political chaos, which can lead to a diminish in economic growth and to unemployment.

Being a member of the European Union is considered to be an economic welfare, especially if the countries are perceived as having an appealing quality of life and a geopolitical positioning within the continent. Last year, EU's economic retrieval has continued, almost all the countries reaching on average a quicker growth than the values registered over the last 3 years.

Using primarily macroeconomic figures, European Systemic Risk Board has drawn the conclusion that although unemployment in the Union continues its descending evolution, this global issue still remains notable in some countries. As an outcome of this problem, it has to be taken into consideration the fact that not only the profitability, but also the solvency of the financial institutions are being affected. However, in all EU countries the current unemployment rate is lower than the three-year average (European Systemic Risk Board, 2017).

Another economic vulnerability regarding uncertain situations across the European Union is represented by the level of indebtedness that some countries and sectors have, making them unstable and unsustainable financially. As for the entire Union's government debt, the extent is surpassing the barrier of $60 \%$ of the total GDP, which is the reference degree 
accepted and acknowledged through the Maastricht Treaty. Although over the last years the indebtedness level has been diminished, the rhythm was less intense than the growth in debts registered in the forthcoming period of the global crisis.

\section{The price of uncertainty in Europe}

A country's personal risk can be seen as a mixture of economic, geo-political, institutional or social factors or, in other words, a country-specific complex reality (Iloie, 2015). On a global scale, 2017 was a gainful year, with just 12 countries in recession, which represents half of the number registered in 2016 and the lowest volume since 2007. Despite this, the geopolitical tensions and uncertainties that exist in the policy domain are leading to a necessity of tools that can help governments identify, acknowledge, determine and monitor the risks. This is why institutions like Coface, a French credit insurer, try to proactively deliver detailed risk forecasts not only for themselves, but also for their customers, easing the decision-making process and preventing the appearance of credit risks. Their analysis include a closer and more detailed look into 160 countries, together with their business climate and risk assessment for more than 10 sectors worldwide.

Ranging from $A$ (which describes a tolerable business climate or a low probability to be exposed to risks) to $E$ (meaning significantly noncompliant economic climate or a high likelihood of certain unwanted events to happen), these indexes are designed to help anyone in making the right choice in the perfect moment.

Table 2: Country Risk Assessment within Europe

\begin{tabular}{|c|c|c|c|c|c|}
\hline \multicolumn{6}{|c|}{ EUROPE } \\
\hline COUNTRY & RISK & BUSINESS CLIMATE & COUNTRY & RISK & BUSINESS CLIMATE \\
\hline Austria & $\mathrm{A} 1$ & $\mathrm{~A} 1$ & Italy & A3 & $\mathrm{A} 2$ \\
\hline Belgium & $\mathrm{A} 2$ & $\mathrm{~A} 1$ & Latvia & A3 & A2 \\
\hline Bulgaria & A4 & A3 & Lithuania & A3 & $\mathrm{A} 2$ \\
\hline Croatia & B & A3 & Luxemburg & A1 & A1 \\
\hline Ciprus & A4 & A3 & Malta & $\mathrm{A} 2$ & $\mathrm{~A} 2$ \\
\hline Czech Republic & $\mathrm{A} 2$ & $\mathrm{~A} 2$ & Netherlands & A1 & A1 \\
\hline Denmark & A2 & A1 & Poland & A3 & $\mathrm{A} 2$ \\
\hline Estonia & $A 2$ & $\mathrm{~A} 1$ & Portugal & $\mathrm{A} 3$ & $\mathrm{~A} 2$ \\
\hline Finland & $\mathrm{A} 2$ & $\mathrm{~A} 1$ & Rumania & A4 & A3 \\
\hline France & A2 & A1 & Slovakia & A3 & $\mathrm{A} 2$ \\
\hline Germany & A1 & $\mathrm{A} 1$ & Slovenia & A3 & $\mathrm{A} 2$ \\
\hline Greece & B & A4 & Spain & $\mathrm{A} 2$ & A1 \\
\hline Hungary & A3 & A3 & Sweden & $\mathrm{A} 1$ & $\mathrm{~A} 1$ \\
\hline Ireland & $\mathrm{A} 3$ & $\mathrm{~A} 1$ & United Kingdom & $\mathrm{A} 3$ & $\mathrm{~A} 1$ \\
\hline
\end{tabular}

Source: COFACE (Compagnie Française d'Assurance pour le Commerce Extérieur, Country \& Sector Risks 2018)

When it comes to Europe, and Romania implicitly, the first notable fact is that our country is perceived to be as "risky” and "favourable” as Bulgaria and Cyprus. Moreover, since 2011 until last year, Romania was given the B score, following the same path together with Greece (B/A4) and Croatia (B/A3). Moving to the leading less insecure countries from the EU, we can observe that Austria, Luxembourg, Netherlands and Sweden represent the peak, being awarded with A1 not only for their reliable domestic market, but also for their qualitative outlook in terms of macro environment and finance. As for the extremely uncertain business climate risks, we can confidently say that in the entire Union the 
presence of some substantial deficiencies has been reduced, together with efforts that are concentrated towards instability and underperformance.

In search of a connection between the members of the European Union, I compared the scores given for the ongoing year, and this is how I came to the conclusion that an A3 risk level within the European economies is the predominant one (10 out of 28 countries), while for the discernible pattern in terms of business climate, the maximum level has been reached by 13 countries, diffusing faith and positivism.

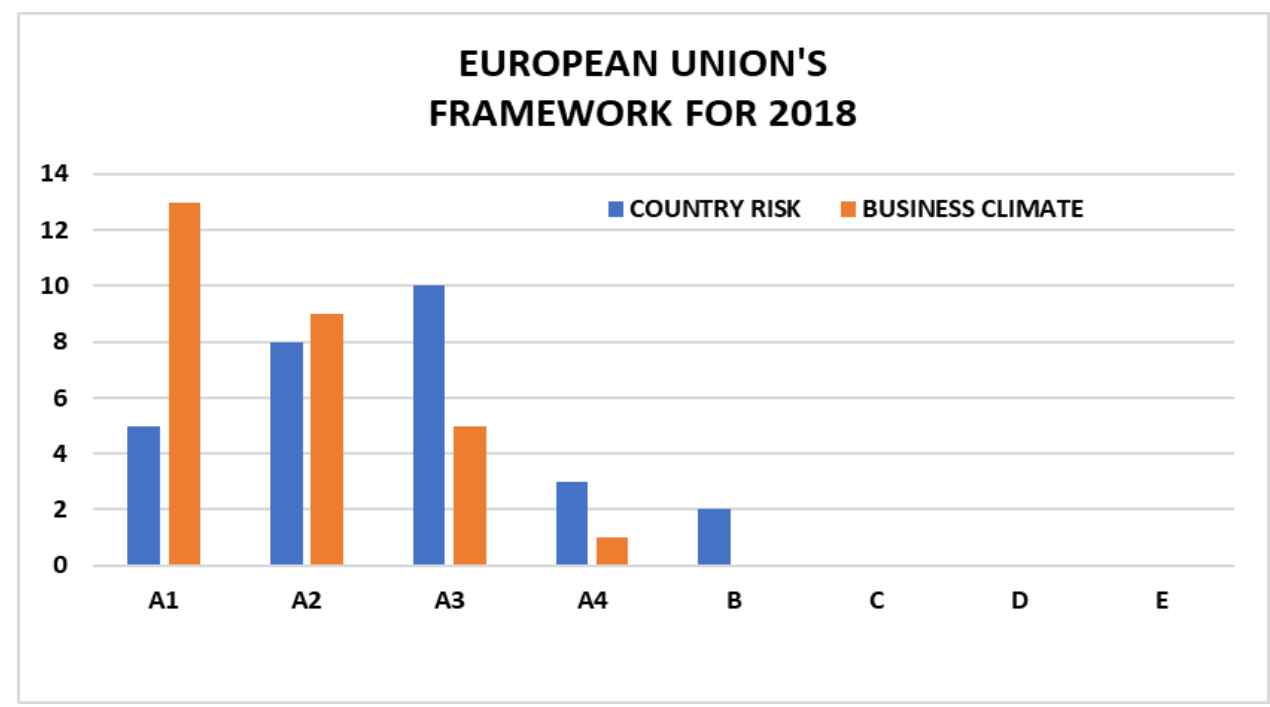

Figure 2: European Union's framework in 2018

Source: Data from COFACE (Compagnie Française d'Assurance pour le Commerce Extérieur, Country \& Sector Risks 2018), own computation.

Quarterly, Coface reviews the assessments of 13 sectors throughout 24 countries in 6 major regions in the world, which represent approximately $75 \%$ of global GDP. The assessment scales on four levels: low, medium, high or very high, in order of increasing risk (COFACE, 2018). Making mention of Central Europe, on one hand, it is expected an increase in risk associated with construction and transport sectors, while, on the other hand, thw Western Europe will face uncertainties in regard to energy, metals, paper and textile-clothing industries.

Romania is perceived as a safe economic climate, but which can exhibit shortcomings anytime. Our financial and business outlook is a reasonable one, in which the political context can release deep pressure. One of the strengths we have is that we possess a remarkable agricultural potential, limited energy dependence (due to coal, oil, gas), diversified and competitive industry thanks to cheap labour (COFACE, 2018). In terms of deficiencies, one of the biggest threats that we have to face is the demographic decline, together with the bureaucracy and the informal economy (approximated at 28\%). 2018 is supposed to bring us low uncertainties in the automotive and pharmaceuticals sectors, while other industries, for example construction and metals will be challenged with a certain degree of risks.

\section{Financial Analysts' Perspectives on Romania}

In a global macroeconomic context driven by uncertainty, it is compulsory to outline an image of how Romania's economy will look like in the next decade. Are the perspectives going to be satisfying? Will the existing companies manage to overlook the multitude of 
challenges or can the state-owned enterprises sustain the economy? In order to answer to these questions is important to identify those firms that are expected to continue being part of the Romanian economy in the next years.

The Romanian economy is constituted to a large extend of mature firms and the future is probably going to follow the same characteristics. The National Bank (Neagu, Dragu, Costeiu, 2017) has identified about 133.000 companies (22\% of the total number of active companies in December 2015) that can be considered the veterans of the Romanian economy, being present in the economy for at least 15 years (double the average lifetime of a firm which operates on the Romanian market). But the problem with these companies resides in the fact that their direct regional presence is a limited one. For instance, according to BNR (National Bank of Romania), between 2005-2015 only 134 Romanian entities penetrated the external markets through foreign investments.

When it comes to the most efficient existing companies in the national economy, the same authors (Neagu, Dragu, Costeiu, 2017) determined 13.100 of such firms $(2,1 \%$ from a total of about 608.000 active companies in 2015), their importance in the economy rising continuously. The methodology for determining the elites of the national economy takes into account the net profit and the production factors that are used (capital and labour). Analyzing the dimension of these firms, it can be observed that the highest percentage is held by the small enterprises $(62 \%)$ and having the branch of the activity as a criteria, it can be noticed that $30 \%$ represents only the manufacturing industry.

The importance in the Romanian economy of state-owned enterprises has been considerably diminished in the last decades, reaching values imminent to the European average. The number of companies with a majority public capital surpassed 1.000 in 2015, this value being six time less than the maximum level that was attained in 1995. Necessary to mention is the fact that the Romanian state-owned enterprises have a majority contribution in the research and development sector, spending $66 \%$ from the total amount of expenses.

When it comes to Romania's economic perspectives, the Chartered Financial Analyst (CFA) Macroeconomic Confidence Index aims to quantify the anticipations of some financial analysts, having a one-year time horizon. This indicator was firstly released in May 2011 by CFA Society Romania and is calculated based on a set of questions. It can take values between 0 , which shows no confidence and 100, highlighting a complete trust in the Romanian economy. Important to mention is the fact that the participants are active members of the CFA Society Romania or candidates for the second or third level of the CFA exams.

In December 2017, the Macroeconomic Confidence Index registered again a decrease, reaching a value of 41.0 points, the lowest result since June 2013. Compared to previous month, the index recorded a decline with 3.1 points, while in January the nominal value was 54.9 , with $34 \%$ higher than this outcome.

Analysing the two elements that compound the index, we can observe that the current conditions component (of business and labour market) exceeded the neutral level with 9 points and managed to attain the nominal value of 59.0, dropping with almost 1 point, when comparing the result with November's figures. At the same time, the expectations constituent (about business, evolution of personal income, labour market, personal wealth) acquired the most inferior position since October 2012, namely 32.0 (CFA, 2017).

But the real and deep problem for the Romanian economy is the fact that also the future looks uncertain and the business conditions seem to be unable to recover, leading to a continuous reduction in the perceived confidence. For instance, when asking which are their expectations regarding the economic environment in Romania for the next 12 months, $74.4 \%$ of the financial analysts answered that the business conditions will worsen, while other $23.1 \%$ believe that the situation will remain the same. Unfortunately, respondents' judgement remains the same also when we bring the employment situation into question, 
more than half expecting things to get worse. The annual inflation rate in the next 12 months is presumed to increase $(97.4 \%$ of the respondents) and RON compared with EUR is estimated to depreciate (92.3\%), no one being able to imagine a positive scenario in regards with these two issues.

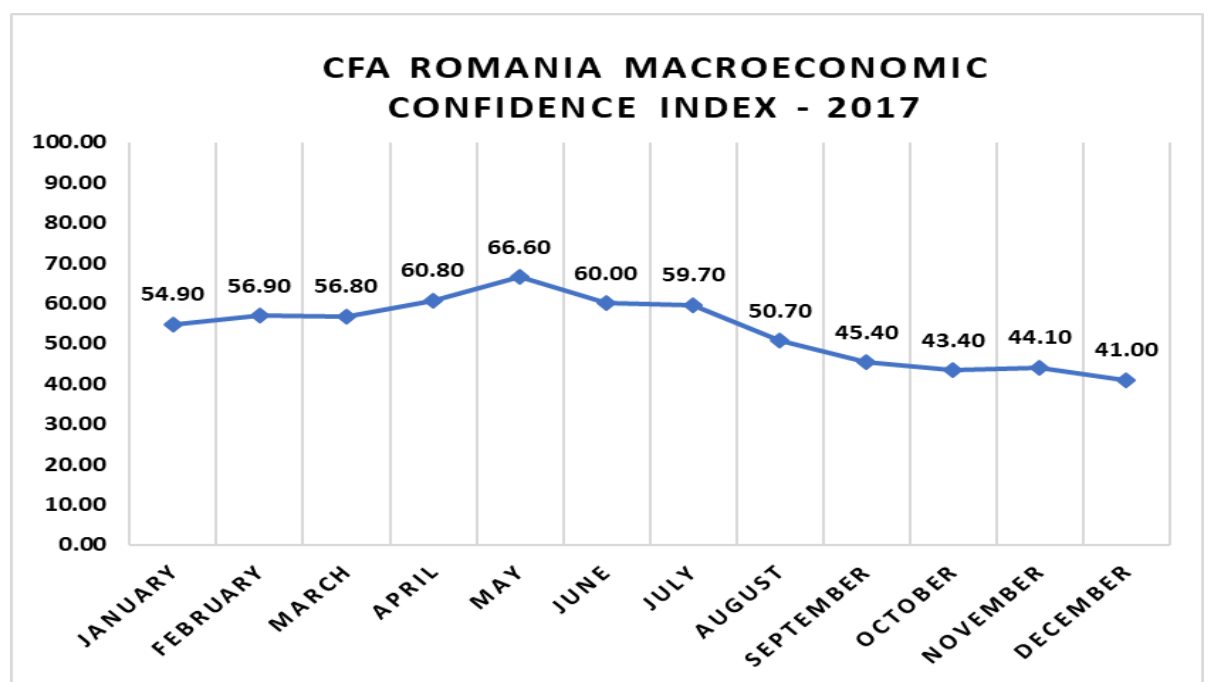

Figure 3: Evolution of the CFA Romania Macroeconomic Confidence Index in 2017 Source: Data from CFA Society Romania (https://www.cfasociety.org/romania/), own computation.

\section{Conclusions}

The presence to a large extend of mature firms in the Romanian economy will accentuate the degree of aging, which can affect the economy's capacity to widely aim towards sectors of the future and readapt the mentality for next decade's requirements.

Although the most efficient companies use capital and human resources more effective than the rest of the economy, I believe that the disparity in relation to the average of the developed countries is still maintained. The productivity is placed above the one registered in other countries from the region, but the values are significantly inferior compared to the developed countries.

The power equilibrium in the Romanian economy is expected to continue unbalancing in favour of the companies that possess a majority foreign capital, making mandatory the implementation of a national policy which will assure an adequate competitive context and an equitable treatment.

As for the working hypothesis, the present article confirms the idea that the real and deep problem for the Romanian economy is the fact that also the future looks uncertain and the business conditions seem to be unable to recover, leading to a continuous reduction in the perceived confidence.

To conclude with, uncertainty's effects about a nation's economic policies can often spread beyond the country's borders. This is why it takes awareness to understand that a stable macroeconomy reduces uncertainty and enables economic agents to focus on productive decisions rather than on trying to mitigate high risks (World Bank, 2014). Indisputable, these are critical ingredients not only for the longevity receipt, but as well for performance. 


\section{References}

Annual Report 2016. European Systemic Risk Board. Available at: https://www.esrb.europa.eu/pub/pdf/ar/2016/esrb.ar2016.en.pdf, [accessed 10.10.2017].

Baker, S. R., Bloom, N., \& Davis, S. J. 2016. Measuring economic policy uncertainty. The Quarterly Journal of Economics, 131(4), 1593-1636.

Besanko, D., Dranove, D., Shanley, M., Schaefer, S. 2010. Economics of Strategy International Student Version, Asia: John Wiley \& Sons Pte Ltd.

BNR. 2017. Raport asupra inflației - august 2017. PDF București: BNR, 57. Available at: http://www.bnr.ro/PublicationDocuments.aspx?icid=3922, [accessed 30.09.2017].

CFA.(2017. CFA Society Romania Confidence Index - December 2017. CFA. available at: https://www.cfasociety.org/romania/Lists/Announcements/Attachments/164/Index\%20Dec \%2017.pdf, [accessed 15.01.2018].

COFACE 2018. Coface Handbook: Country \& Sector Risks 2018. Available at http://www.coface.com/News-Publications/Publications/Analysis-and-forecasts-for-160-co untries-and-13-sectors, [accessed 17.01. 2018].

European Systemic Risk Board, The ESRB risk dashboard: an overview, Issue 22. Available https://www.esrb.europa.eu/pub/pdf/dashboard/20171220 overviewnote.en.pdf?a06c985 ed59fec8a7dc413e229c2fe0a, [accessed 15.01.2018].

Iloie, E.R. 2016. Connections between FDI, Corruption Index and Country Risk Assessments in Central and Eastern Europe. Procedia Economics and Finance, 32, pp. 626-633.

Neagu, F., Dragu, F, Costeiu, A. 2017. Pregătiți pentru viitor? O nouă perspectivă asupra economiei României. București: BNR, 29. Available at: http://www.bnr.ro/Caiete-de-studii-484.aspx, [accessed 07.10.2017].

World Economic Forum 2017. The Global Risks Report 2017, available at http://www3.weforum.org/docs/GRR17 Report web.pdf, [accessed 04.10. 2017].

World Economic Forum 2018. The Global Risks Report 2018, Available at: http://www3.weforum.org/docs/WEF GRR18 Report.pdf, [accessed 04.10. 2017].

Tversky, A., Kahneman, D. 1992. Advances in Prospect Theory: Cumulative Representation of Uncertainty. Journal of Risk and Uncertainty, 5(4), pp. 297-323.

World Bank 2014. World Development Report 2014. Available at: http://siteresources.worldbank.org/EXTNWDR2013/Resources/8258024-1352909193861/ 8936935-1356011448215/8986901-1380046989056/WDR-2014 Complete Report.pdf, [accessed 12.07.2017].

World Bank 2017. World Development Report 2017. Available at: http://www.worldbank.org/en/publication/wdr2017, [accessed 20.01.2018].

\section{Bio-note}

Drăghici Dalis Maria is a PhD student at "Lucian Blaga" University of Sibiu from Romania Faculty of Economic Sciences. As a first-year member of the Management department, Dalis has chosen to conduct a research analysis on risk and uncertainty, by correlating their financial and economic effects with the investment processes. 